\title{
Tijera contra papel. Vetos y obstaculizaciones a la música underground: el caso vasco
}

\author{
Tijera contra papel. Vetoes and Barriers to Underground \\ Music: the Basque Case
}

David Mota Zurdo · David.mota@ui1.es

UNIVERSIDAD ISABEL I

Recibido: $15 / 10 / 2018$

Aceptado: 17/11/2018

\section{Resumen}

En el presente artículo se analiza la trayectoria del grupo musical vasco Berri Txarrak en el contexto underground español. Se cruza con las opiniones vertidas por los medios de comunicación generalistas y se presta especial atención a los medios coercitivos que ha utilizado el aparato punitivo del Estado para desde entonces sancionar ciertas expresiones culturales en detrimento de otras durante la etapa democrática. Todo ello, se aborda desde una perspectiva metodológica descriptiva del contexto y analítica del discurso y busca problematizar la cuestión de los límites de la libertad de expresión, estableciendo nexos pasado-presente, que tanto están afectando a día de hoy al medio cultural español.

Palabras clave: Música underground, España, Berri Txarrak, Libertad de expresión, Censura.

\section{Abstract}

This article analizes the trajectory of Berri Txarrak — the Basque Musical Group — in the Spanish underground's framework. It intersects with the opinions expressed by the generalist Media and special attention is paid to the coercive means that the State's punitive apparatus has used since then to penalise certain cultural expressions to the detriment of others during the democratic period. All this is approached from the methodological descriptive perspective and analytical of the discourse, and seeks to problematize the question of the limits of freedom of expression, establishing past-present links, which are affecting the Spanish cultural environment to this day.

Keywords: Underground Music, Spain, Berri Txarrak, Freedom of expression, Censure. 


\section{INTRODUCCIÓN}

Actualmente, la persecución a la música underground y a la contracultura, es decir, a todo aquello que critique al establishment, es un hecho consumado. La paradoja está en que este tipo de vetos y dificultades reaviva y fomenta la proliferación de los elementos subversivos y contrarios al sistema hegemónico que persiguen algunos gobiernos. Si el tabú, la ley y las costumbres establecen nuevas limitaciones, lo habitual es que emerja una corriente, residual o no, que ininterrumpidamente apueste por expandirse, a modo de acción terapéutica de alivio y expresividad (Freud, 1966: 95). En este ámbito, la cultura underground ha ejercido un papel nuclear en la emisión de opiniones contracorriente, porque su objetivo siempre ha sido combatir la constante dominación parental, sea un Estado o un Gobierno, que subyuga y controla el conocimiento y las diferentes formas de expresión (Álvarez, 2013: 147). Así es como surgen grupos musicales, escritores, autores teatrales que no asimilan, ni asumen, ni aceptan la alienación que se produce a su alrededor.

En los últimos años, raperos como Valtonyc, La Insurgencia, Los Chikos del Maíz, Pablo Hásel o los famosos titiriteros han sido denunciados por enaltecimiento del terrorismo, insultos a la corona o por ofensas contra la religión por el contenido de sus letras y sus manifestaciones públicas. Se trata de grupos músico-artísticos que se han situado habitualmente en la órbita de la izquierda, manteniendo una opinión distinta a la oficial y, por ello, han sido considerados excéntricos y elementos marginales extremistas que dificultan el normal desarrollo de la vida social.

Todos estos casos proceden de una dinámica anterior. De un proceso cultural y político que los grupos musicales underground vascos sufrieron a partir de los años 80, si se considera como tal la incomunicación de Eskorbuto durante 36 horas en Madrid. Y que se acrecentó con los procesamientos judiciales de Negu Gorriak y Soziedad Alkoholika (S.A.) durante las décadas de 1990 y 2000.

El grupo que se ha elegido para ilustrar todo este fenómeno es el navarro Berri Txarrak. Lo más accesible habría sido analizar los casos de S.A. y Negu Gorriak, que son sobradamente conocidos y han tenido una importante repercusión en la prensa, pero se ha optado por la banda navarra porque sus problemas apenas han tenido impacto mediático. También se ha hecho así por rellenar cierto vacío en las investigaciones de este tipo, ya que, es un grupo al que se ha prestado escasa atención, aún llevando más de 20 años en activo, y, porque siendo internacionalmente reconocido, se ignoran sus problemas con ciertos medios de comunicación y sectores políticos.

\section{ACLARACIONES METODOLÓGICAS}

La metodología de esta investigación se basa en dos vertientes, por un lado, un análisis descriptivo centrado en los aspectos sociales, políticos y culturales de los años 80 a la actuali- 
dad, y, por otro, el examen crítico del discurso en una organizada secuencia de testimonios y extractos de noticias aparecidas en los principales periódicos generalistas. En lo que respecta al análisis de éstos se presta especial atención a los campos semánticos en los que se subrayan las relaciones de poder y la utilización de dispositivos ideológicos de subjetivación de las mentalidades. Respecto a la utilización de unos testimonios en detrimento de otros cabe señalar que se han aprovechado restos de entrevistas realizadas para el largometraje documental Tijera contra papel. Historia de la nueva censura, en el que he colaborado como co-guionista. Asimismo, se ha evitado entrar en discusiones historiográficas y conceptuales en torno a la utilización de música underground y Rock Radical Vasco (RRV). De hecho, aquí se utilizan como sinónimos, pese a que en otra parte (Mota, 2017b) se ha explicado profusamente sus matices, diferencias y concreción. Por eso, en lo que concierne al concepto de RRV remito a los principales autores (Del Amo, 2016; Dávila y Amézaga, 20032004; Atutxa, 2014; Larrínaga, 2014; Porrah, 2006; Pascual, 2015; López Aguirre, 2011).

\section{PELIGRO: MÚSICA UNDERGROUND}

¿Cómo entender el veto y boicot a la música contestataria? ¿Cuándo comienza? ¿En qué contexto? Hay que remontarse a los años de la Transición para obtener una radiografía al respecto. Los años de la década de 1980 fueron de desenfreno, radicalidad, empoderamiento y adicción. De mensajes contestatarios y sin cortapisas, de pintadas en las calles con mensajes políticos y de desencanto, de utilización de todo tipo de formas de expresión para producir canales de cambio. De nuevas formas de protesta, de manifestaciones y de lucha por los derechos sociales, políticos y civiles con el fin de mejorar la calidad de vida de la ciudadanía (Ramos, 2008: 211). Tiempos de pancartas, panfletos, revistas, fanzines, carteles, pegatinas, asambleas, huelgas y encierros, y de nuevas oportunidades políticas tras la mordaza impuesta por la dictadura franquista durante casi cuatro décadas. Fueron años marcados también por la contrainsurgencia, el plan Zona Especial Norte, el terrorismo de ETA, las torturas, el GAL, la extrema izquierda, el nacionalismo, los intentos de golpes involutivos, los pactos, el enfrentamiento, las luchas obreras, vecinales y estudiantiles, y la movilización ciudadana. Tiempos de intento de ruptura con el pasado, de cambio social, político y cultural, de construcción del sistema democrático. Años, en definitiva, en los que la música rock se presentó como un vehículo posibilista de comunicación, de conexión con la rebeldía y el inconformismo juvenil, de expresión de sentimientos palpables y compartidos por la sociedad, de profundización en discursos metafísicos e identitarios, de contrainformación, de búsqueda de la verdad, de duda, de radicalidad y de compromiso ideológico (Romero, 2018: 28-33; García Salueña, 2013: 37).

Si bien no todo fue una apuesta por el progreso de la naciente democracia. Las ansias de cambio se vieron paralizadas en algunos casos ante el gran número de «quietos, integrados y sumisos, partidarios de cambiar algunas cosas - por supuesto, aquella dictadura y sus formas-, pero no de cambiarlo todo» (Rivera, 2015: 25-26). La Transición fue, como ha se- 
ñalado Fernández Soldevilla, una época convulsa y complicada que se caracterizó por contener altas dosis de improvisación y en la que participó un heterogéneo grupo de actores que con su intervención hicieron posible el avance democrático (Fernández, 2015: 34-35).

Un cambio que, por otro lado, fue posible en múltiples aspectos, entre ellos, el cultural. Ya, durante la dictadura, el régimen había perdido el dominio de la cultura sobre las generaciones más jóvenes. Una cultura marcada fuertemente por la presencia del integrismo nacional-católico y las referencias retóricas al Siglo de Oro que se utilizaban como símbolos patrios. Sin embargo, parte de la cultura de los años de la Transición fue próxima a la contraculturalidad, a la izquierda libertaria y al nacionalismo. Este ambiente se vio favorecido gracias a la relajación de la censura que se produjo con Manuel Fraga al frente del Ministerio de Información y Propaganda (década de 1960, años del aperturismo franquista), pues con él se sustituyó la Ley de prensa de 22 de abril de 1938, que exigía la censura previa a la publicación y que estaba al servicio de los intereses y valores de la dictadura, por la Ley 14/1966, de 18 de marzo, que eliminó la censura previa, aunque mantuvo fórmulas como el secuestro editorial. Ahora bien, esta teórica atenuación no supuso a corto plazo (ni a largo) ningún cambio de objetivos, pues al final el control a todo tipo de elementos subversivos u oposicionales al régimen continuó siendo su principal cometido (Sarría Buil, 2006: 574; Bassets, 2013).

Durante la década de 1960, en el País Vasco como en otros lugares industrializados, se produjo una llegada masiva de inmigrantes que se asentaron en torno a las principales ciudades, en barrios aislados, deficitarios de dotaciones colectivas de tipo cultural, sanitario, recreativo y de zonas verdes, y de un insuficiente entramado viario de acceso (Alonso Olea, 2002: 20; García Herrera, 1990: 37). En las mentes de las personas residentes en estos lugares se fue cuajando un sentimiento de conciencia colectiva con la finalidad de reclamar mejores condiciones de vida y derechos. Estas inquietudes, sumadas al creciente número de universitarios procedentes de las clases medias, dieron lugar a una asociación con la población trabajadora. A la postre, esta alianza fue el germen para que se produjera el crecimiento de una identidad y una cultura popular de barrio. La cultura de la sociedad trabajadora encontró en los sectores juveniles, principalmente los universitarios de clase media, un excelente socio que, a posteriori, ya en el tardofranquismo, ayudó a crear un espacio de crítica al régimen, underground, de cultura popular, y, así, como ha señalado Burutxaga: «fue desapareciendo la censura, se eliminó la barrera entre autores del interior y del exilio, y con algunos secuestros y multas, la libertad de expresión fue avanzando» (Burutxaga, 2015: 230).

Este caldo de cultivo previo permitió, durante los años de la Transición, el avance en la reclamación de derechos en materia de ecología, feminismo, y minorías étnicas, lingüísticas y de orientación sexual, al que se sumó, entre otras cosas, la lucha por la recuperación y la visibilización del euskera en el ámbito público (López Romo, 2011). No obstante, un público heterodoxo porque de la misma manera que demandaba productos culturales anglosajones no menospreciaba a artistas del régimen como Raphael. 
Con la entrada del socialista Felipe González en la Moncloa estas reivindicaciones se tiñeron de pragmatismo, hedonismo y consumo. La libertad en la década de 1980 pasó de ser un fin alcanzable por el que luchar a convertirse en un elemento de pleno disfrute. La Movida madrileña, la estética estrambótica, la música de radio-fórmula disfrazada de alternativa, los punks, la heroína, la crisis económica, la contaminación, bares, gaztetxes, conciertos y el rock se convirtieron a partir de ese momento en algunos de los principales ingredientes del ámbito cultural (Beorlegui, 2017; Vilarós, 2018). Pero, los coletazos involucionistas también. Fruto del proceso de cambio, que ni fue uniforme ni unísono, aparecieron retazos del pasado dictatorial en ámbitos tan dispares como el musical, especialmente, en el denominado Rock Radical Vasco (RRV), un género musical que desde sus inicios estuvo vinculado a la política ${ }^{1}$. De hecho, sus acciones, su crítica al sistema, su pretensión de destruirlo no fue bien visto por el establishment, no sólo porque ponía en solfa los cimientos del sistema político, sino porque lo hacía desde el punk y de corrientes cercanas al movimiento obrero, a la izquierda libertaria, a la acracia, al anarquismo y, a un nivel más micro, a la izquierda abertzale (Larrínaga, 2014: 127 y ss; Mota, 2018a: 39 y ss.).

Efectivamente, desde los tiempos del RRV, este compromiso no ha sido bien visto por los partidos políticos, grupos de presión y asociaciones de ideología conservadora que han considerado a estos grupos, sean de la ideología que sean (pero, basta con que sean críticos con el sistema), una especie de brazo musical radical, anti-sistema, subversivo y proterrorista $^{2}$. Durante casi tres décadas, con especial vehemencia durante esta última, estos medios de la conocida como caverna mediática se han dedicado a generar contenido que intoxica la labor artística de estos grupos musicales a los que critica e, incluso, denuncia por el contenido político y contestatario de sus composiciones ${ }^{3}$. Simplifican hasta el extremo las letras, las descontextualizan seleccionando extractos morbosos que explican

\footnotetext{
${ }^{1}$ Se debe tener en cuenta que previamente a la emergencia de la etiqueta del RRV hubo un movimiento, un caldo de cultivo que permitió su eclosión. El término apareció por primera vez en Egin el 16 de octubre de 1983 y fue acuñado por los periodistas José Mari Blasco y Pablo Cabeza y el productor musical Marino Goñi. Éstos dieron a conocer el término de RRV, un sonoro nombre tras el cual se encontraban los poderosos y lucrativos objetivos de vender la música que se estaba haciendo en el norte al resto de España, contrarrestar la capacidad de atracción que generaba la Movida Madrileña y hacer frente a la potencialidad de su mercado. Todos ellos, por diferentes intereses, lograron, primero, estabilizar, y, posteriormente, consolidar, la escena rock vasca (Mota, 2018b). Como ya se ha adelantado, el RRV estuvo precedido de un movimiento de resistencia juvenil, caracterizado por la adopción de una cultura radical organizada en torno al fenómeno punk; que tuvo la calle, los bares, las casas okupadas, las radios libres, los conciertos, los fanzines y la música como un microcosmos, con sus canales de comunicación propios y sus vías de manifestación pública, alternativas a la cultura hegemónica -dominantemente conservadora-(Pascual, 2015: 67). Ahora bien, la vinculación de dicha escena con la política generó diferentes tensiones entre los grupos punk más nihilistas como Eskorbuto y otros como Kortatu (Mota, 2018: 415 y ss.; Mota, 2016: 335-354; Sáenz del Castillo, 2012: 119-141). Opiniones dispares y/o ambiguas en (Porrah, 2006; López Aguirre, 2011).

2 Esta actitud (anti-)establishment hunde sus raíces en la Transición (Del Amo, 2016: 57; Porrah, 2006).

${ }^{3}$ El término de caverna mediática o Brunete mediática fue una etiqueta popularizada en la década de 1990 por un grupo de políticos nacionalistas vascos, entre los que se encontraban los jelkides Xabier Arzalluz e Iñaki Anasagasti. Éstos acuñaron esta denominación para definir a los medios de comunicación ligados a posturas conservadoras, muy críticos con el nacionalismo vasco, a raíz de la interpretación que la derecha española había hecho sobre el Pacto de Estella de 1998 entre PNV, EA, HB, IU, EKA y fuerzas sindicales y sociales, viéndolo con recelo por su cariz independentista, para ellos, sinónimo de violencia y peligrosidad. No obstante, desde mediados de la década de los 2000 esta etiqueta comenzado a ser utilizada principalmente por los partidos políticos de izquierda para referirse a los medios de comunicación cercanos al Partido Popular.
} 
con argumentos escasamente fundamentados, y asocian así sus ideas con lo políticamente incorrecto.

Una cuestión que, por otro lado, no es nueva. Desde la década de 1960, la gran mayoría de los grupos musicales underground sólo han sido noticia para los medios de comunicación generalistas cuando de por medio ha habido cuestiones negativas, morbosas, escabrosas y polémicas. Así, resulta lógico que, después de tantos años siendo receptores de este tipo de bombardeo mediático, la primera imagen que a uno le venga a la cabeza al hablar, por ejemplo, de los Sex Pistols sea la de un Sid Vicious desaliñado con una jeringuilla de heroína pegada a su brazo. Esa imagen se ha utilizado en reiteradas ocasiones como contenido moralizante, para mostrar a los jóvenes de ahora que aquellos años de desenfreno y adicción tuvieron enormes consecuencias para la generación que alcanzó la mayoría de edad entre finales de la década de 1970 y principios de la de 1980. De hecho, ha sido un lugar revisitado incluso por la izquierda abertzale, que al inicio de los años 80 atacó a la música punk sacando a relucir sus aspectos más espurios:

Primero, se crea una necesidad. Luego se cubre dicha necesidad. Es el proceso que aquí se está siguiendo. Los valores del american way of life, tan desprestigiados, están siendo adecuados para el tiempo futuro [...]. En esta estrategia se inscribe, por ejemplo, la entronización de modelos culturales de dudosa validez. Se ensalza a Jimmy Hendrix —el sonido de su guitarra, te ponía en contacto con los dioses, dicen-, pero se considera como algo anecdótico que Hendrix babeara y anduviera a cuatro patas cuando le faltaba su picotazo de heroína. Se ensalza a Janis Joplin — su voz desgarrada, te ponía la carne de gallina- pero la Joplin cascó muy pronto, víctima de una sobredosis. Se ensalza a Sid Vicious - era el Pepito Grillo de una sociedad hipócrita- pero, cuando apareció muerto en una habitación de un hotel neoyorquino, las agujas hipodérmicas habían hecho su labor y los brazos de Vicious eran un pura llaga ${ }^{4}$.

Evidentemente, esto es innegable, pero sólo es una parte de lo que fue el punk y resulta injusto que haya sido tan estereotipado.

Con todo, si el punk ha sido atacado asociándolo a la droga y la destrucción, sus herederos tampoco han salido mejor parados. Al profundizar en los géneros musicales coetáneos y posteriores al punk, caracterizados por su compromiso político (hardcore, el hip hop y el rap-metal) y por dejar atrás el no-future del punk proponiendo alternativas frente a la simple denuncia, se observa que los medios de comunicación más conservadores han emitido una imagen de ellos que es, incluso, más negativa.

Un fenómeno generalizado y no exclusivo del territorio español, en el que la prensa conservadora y más complaciente con el establishment se ha dedicado a equiparar la música underground con los peligros para la democracia. Por ejemplo, los grupos estadouniden-

\footnotetext{
${ }_{4}^{4}$ "Y ahora la droga», Punto y Hora de Euskal Herria, 170, 1980, 14.
} 
ses Public Enemy, Rage Against The Machine, Fugazi, Minutemen y Bad Brains han sido estigmatizados dentro de la sociedad americana al vincularles con la violencia, la droga y la delincuencia; en algunos casos, por el simple hecho de ser de raza negra y de barrio (estereotipo muy manido entre los medios de comunicación norteamericanos de la década de 1980) y, en otros, por formar parte de movimientos anti-imperialistas e internacionalistas contrarios a la desigualdad socio-económica y partidarios de la justicia social (Lenore, 2015: 129). Es más, a estos colectivos se les debe la conocida etiqueta de Parental Advisory: Explicit Content que la Record Industry Association of America (RIAA), asociación de la industria magnetofónica americana, tuvo que colocar en los discos que tenían composiciones con lenguaje subversivo. Así, el hecho de formar parte de este entramado ha sido interpretado desde posturas conservadoras como sinónimo de estar en contra de los intereses de Estados Unidos y, por tanto, de situarse en el lado antipatriota y antisistema.

De este modo, si se toma en consideración este fenómeno generalizado, se pueden encontrar ciertas similitudes con el caso español. Los grupos con letras más comprometidas políticamente, principalmente vascos, pero también de otras partes de España, han sufrido cierta estigmatización por parte de la prensa conservadora, las asociaciones de víctimas del terrorismo y las instituciones políticas. Los medios de comunicación conservadores han construido una imagen que roza lo esperpéntico de algunos grupos vascos como Fermín Muguruza, Sutagar, Soziedad Alkoholika (S.A.) o, el que aquí se trae a colación, Berri Txarrak, a los que han tildado de pro-terroristas, brazo musical del Movimiento de Liberación Nacional Vasco (MLNV) y arma propagandística de ETA; en muchos casos, simplemente por cantar en euskera, expresar su forma de concebir el mundo y proponer alternativas a la cultura hegemónica.

Pero, si se parte de la concepción de que la música es una forma de expresión, cuyo contenido puede ser real o ficcionado, mediante la que se puede manifestar una situación de malestar hacia aspectos de la cotidianidad, la política, el amor, la economía y la filosofía, proponer soluciones aplicables o utópicas y, en definitiva, expresar emociones, porque en último término la música es transmisora de ideas y como tal debe ser respetada junto con la libre creación artística, resulta verdaderamente controvertido que el establishment haya intentado vetar a las bandas musicales y generar dificultades a su creación musical. Es controvertido, pero no ilógico porque responde al discurso estratégico de tener todo bajo controls; por eso, como se puede comprobar a través del caso de Berri Txarrak, los medios de comunicación se utilizan como una especie de «policía del pensamiento» (Foucé, 2008).

\section{ISTOP CRIMINALIZACIÓN!}

El inicio de la década de 1990 estuvo marcado por la constatación de los estragos generados por la heroína, el estancamiento económico, las diferencias sociales y el contexto de

\footnotetext{
${ }^{5}$ Sobre el establishment y la manipulación (Jones, 2015: 25).
} 
violencia producido por ETA y los GAL (Usó, 2015: 121-156; Arriola, 2016). Fueron años difíciles en los que se generó una atmósfera que influyó negativamente sobre los grupos musicales. Un contexto adverso que, en parte, provocó la injustificada sobrerrepresentación de las bandas de la Movida madrileña y el naciente indie en los medios de comunicación, pues llamaban más la atención que el RRV, aunque no tuvieran su potencialidad comercial. Roberto Herreros e Isidro López han considerado que esto responde a los intentos de imponer una cultura musical favorable a los intereses de los gobernantes, sino no se puede explicar que grupos como Kortatu y La Polla, que vendieron más de 100.000 discos sin apoyo de los medios de comunicación generalistas, recibieran tan poca atención y, en cambio, otros, como La Frontera, que vendieron en torno a 15.000 ejemplares, aparecieran con tanta asiduidad (Herreros y López, 2013: 112).

Llegó un momento en que la situación se invirtió, concediéndoles cierta atención, pero no fue por su música, sino por motivos polémicos. En un pequeño espacio de tiempo, todo el rock político estatal (lo underground) fue considerado subversivo, principalmente el RRV, y se le asoció al entorno de ETA, la izquierda abertzale y el radicalismo. Su notoriedad estuvo vinculada, pues, al terrorismo durante buena parte de la década de 1990 y principios de la del 2000. Tiempos en los que ETA era uno de los principales obstáculos para la normalización democrática en España y el País Vasco y, así, era interpretado por las instituciones españolas y los medios de comunicación generalistas (López Romo, 2015: 63 y ss.). En este pack, se incluía, además, a los partidos de izquierda abertzale, considerados un frente político que gozaba del capital simbólico de ETA, de sus potenciales votantes y de sus dirigentes.

Fue en este contexto en el que la ecuación RRV=ETA cuajó en los medios de comunicación. Una fórmula aún vigente, aunque con ciertos matices diferenciadores, que está tan arraigada en el imaginario de la prensa conservadora que, incluso en el actual contexto del fin de ETA, la izquierda abertzale y todo lo relacionado con lo underground en el País Vasco suele ser denigrado sistemática e impunemente, acusado de fomentar la violencia y de realizar apología al terrorismo, cuando, por un lado, la situación es más compleja y porque, por otro, se deben valorar cuestiones como la evolución ideológica de los protagonistas y su relajación/radicalización de posturas (Letamendia, 1997). La arquetipificación de lo radical en la música reivindicativa ha acabado provocando el desprestigio que siempre ha buscado el mainstream para debilitar a su adversario. La música underground es considerada peligrosa por el contenido de sus letras, por despertar emociones incómodas para la cultura dominante y por revelar actitudes en los sectores juveniles que promueven el cuestionamiento del régimen político establecido.

Una problemática a la que se suma el contexto musical estatal. Desde hace más de 35 años, la sociedad española ha asistido a un evidente proceso de homogeneización cultural. Un proceso que tan sólo es una de las ramificaciones de otro más global, iniciado hace apenas 15 años e identificado como revival de la escena ochentera, que se define como fenómeno indie/independiente/alternativo (Del Amo, 2016: 177 y ss.). Aunque se disfracen bajo 
conceptos y estéticas diferentes, los valores artísticos son idénticos a los de la Movida Madrileña: meritocracia, mitomanía y anglofilia, aderezado por un esnobismo elitista y cierta ideología arcaizante y fascistizante. Tanto la escena ochentera como el actual movimiento indie ha sido apoyado indistintamente por los partidos mayoritarios clásicos de España: PP y PSOE, porque, evidentemente, «a la clase dominante le interesa apoyar ciertas escenas como disolvente de los conflictos sociales, en vez de las distintas subculturas que la cuestionan políticamente» (Lenore, 2014: 141-143). Esta escena musical minoritaria ha sido introducida a través de diferentes campañas publicitarias como símbolo de lo moderno y lo alternativo, a la par que se han denostado otros géneros musicales como el heavy, el punk, el rock duro, el hardcore, el metal, el hip-hop, algunos con mayor público —si cabe- que el mencionado indie.

Lo primero que cabe preguntarse no es el porqué de su persecución sino ¿por qué ahora? Evidentemente, la explosión de la calle que ha supuesto el 15-M de 2011, el ascenso de los partidos de izquierda como Podemos, los movimientos anti-desahucio, el Nuit-Debout, en definitiva, los movimientos por la dignidad, han demostrado la disposición de la gente a salir a la calle y a recuperar su capacidad de presión e influencia. Un proceso que no es exclusivamente español ni europeo, sino que forma parte de un movimiento generalizado a escala global que se popularizó con la conocida primavera árabe de 2010 y el ciberactivismo de grupos como Ponte en pie y Democracia Real Ya! en 2011, si bien, hubo movimientos pioneros como el Black Bloc ${ }^{6}$. Posteriormente, estos grupos y otras iniciativas similares han dado lugar al movimiento de los indignados en España (15M) y han sido inspiración para otros fenómenos como el Movimiento Occupy en Estados Unidos, YoSoy132 en México, la Generación de los 700 euros de la plaza sintagma de Grecia y, recientemente, el Nuit Debout francés.

Todos estos movimientos son el fiel reflejo del estado de repolitización en el que está inmersa la ciudadanía, que ha surgido del hastío de una parte de esta frente a unas instituciones a las que consideran escasamente representativas; movimientos que nacen con el objetivo de promover una democracia más participativa, alejada del bipartidismo y el control que ejercen las grandes multinacionales y la banca sobre las políticas estatales, y partidario de mejorar la calidad del sistema democrático mediante el aumento de la transparencia y la devolución a la sociedad de su poder y capacidad de decisión e influencia (Letamendia, 2013: 252).

A lo largo de este proceso, se han producido múltiples formas de expresar el descontento, el desencanto y el hartazgo hacia el estado de las cosas, y la música ha sido uno de ellos.

\footnotetext{
${ }^{6}$ Aunque Black Bloc hace directamente alusión a la táctica de manifestación utilizada por el activismo anarquista alemán de finales de los 70, desde los años 80 y especialmente a partir de la entrada en el nuevo siglo ha pasado a formar parte de la estrategia de movilización anarquista, autonomista, antinuclear y antigloblalización desde Alemania a Estados Unidos, pasando por Italia y España (Purkis y Bowen, 2004: 33; Ferrándiz y Feixa, 2005: 205; Della Porta y Diani, 2006: 250). Sea como fuere, es un antecedente directo de los movimientos mencionados, sobre todo, tras el impulso de la ciber-red global independiente que se consolidó con la creación de Indymedia, germen de un gran número de movimientos antiglobalización (Monge, 2017: 211).
} 
Pero, no cualquier tipo de música, sino la contestataria, la crítica con el sistema, ya que la canción de radio-fórmula y el indie son parte de la banda sonora que los partidos hegemónicos han utilizado para mostrarse modernos ante el electorado.

Por ejemplo, en 2005, la otrora presidenta de la Comunidad de Madrid, Esperanza Aguirre, reservó un millón de euros del presupuesto para celebrar el 25. ${ }^{\circ}$ aniversario de la Movida; un movimiento estratégico para fagocitar un símbolo de la Transición y del progreso, aceptado por los partidos políticos clásicos, que ha pasado a la historia como políticamente correcto, pese a haber sido inicialmente un fenómeno underground marcado por el desenfreno y la ruptura con la sociedad tradicional. El mencionado apoyo económico levantó revuelo en su momento por mostrar contradicciones, al haber sido el PP uno de los partidos más críticos con este movimiento ${ }^{7}$. Esta asociación con la Movida también fue impulsada por parte de una intelligentsia cultural que se creó en los años 80 y que sigue presente en los principales circuitos musicales, ocupando espacios radiofónicos y de telebasura. El caso paradigmático es el de Olvido Gara:

[Alaska] se ha convertido en referente y emblema de la cultura indie y hípster, y ello a pesar de no tener reparos en fotografiarse con Esperanza Aguirre, participar en tertulias con un icono neocon tan radical como Jiménez Losantos o ejercer de jueza en concursos de talentos. En una entrevista reciente en la que se declaraba anticomunista y profesaba su admiración por la nueva reina de España, se lamentaba también de los prejuicios que siguen existiendo contra gente que, como ella, sigue vistiendo diferente y tiene un discurso distinto al dominante. (Lenore, 2014: 23)

La mayoría de los artistas que en la actualidad se denominan indies en este país no están ligados a lo ético, sino que «su independencia es estética»; se sienten cercanos al negocio musical, al poder y a la cultura y, por tanto, son muy dependientes del dinero público, lo que - en parte - facilita su disposición a llevar a cabo un discurso neutro en las letras de sus canciones (Paskual, 2013: 68). Quizá por ello, algunos políticos actuales se han declarado abiertamente seguidores de la música indie, como ocurre con los socialistas Eduardo Madina (fan de Los Planetas y Beach House) y Patxi López. Este último, durante su mandato al frente de la lehendakaritza (2009-2012), fue entrevistado para la revista musical Rolling Stone, mostrándose como un melómano empedernido y ferviente seguidor de los grupos del último grito en el mundo del rock indie. Así, grupos de este entorno como los Punsetes han declarado que: «Patxi López es un tío muy majo, que no nos dio la brasa y que ama la música sin andarse con hostias [...]. Es un rockero profesional cuyo hobby es la política» (Méndez, 2009). Pero, el mencionado López también se ha declarado haber sido seguidor de Kortatu durante su juventud, bailando el «sarri-sarri» en más de un concierto, y ha asegurado haber crecido escuchando Leño y Asfalto, aunque ahora se decante por Vetusta Morla y Shearwater (Foguet y Simon, 12-4-2016).

\footnotetext{
7 «Aguirre gastará un millón en un homenaje a la movida madrileña», El País, 15-11-2005, en http://elpais.com/ diario/2005/11/15/madrid/1132057454_850215.html
} 
Mientras el establishment ha primado la Movida y el indie, con cantantes de entonces, como la mencionada Alaska y el polifacético Loquillo, y de ahora como Vetusta Morla, Mishima y la Habitación Roja, ha obstaculizado, boicoteado y silenciado a otros grupos. Algunas bandas con una larga trayectoria como Fermín Muguruza, Soziedad Alkoholika y Def Con Dos y otros más recientes como los raperos Pablo Hásel, los Chikos del Maíz, Valtonyc y el colectivo de La Insurgencia, entre otros. Bandas, todas ellas, que están viendo afectadas por la deriva homogeneizadora de la cultura musical y las acusaciones que vierten sobre ellas en cuanto a su supuesta vinculación con el denominado entorno de los radicales antisistema. Una situación agravada por las dificultades que genera la Ley de protección y seguridad ciudadana de 2015, la conocida como Ley Mordaza, una normativa que «trata de enjaular el arte y la libertad de expresión» (Escribano, 24-3-2016).

Partiendo de estas consideraciones, se analizará la situación que atraviesan un buen número de grupos ubicados dentro de la música contestataria. A continuación, se examina la trayectoria y problemática que sufrió el grupo navarro Berri Txarrak, ejemplo paradigmático de lo ocurrido a los grupos underground vascos, simpatizantes (o no) de la izquierda abertzale, encasillados, boicoteados y estigmatizados por la crudeza de sus composiciones, su procedencia y la utilización del euskera como lengua vehicular.

\section{EL CASO DE BERRI TXARRAK}

Berri Txarrak, grupo natural de Lekunberri (Navarra), liderado por el guitarrista y vocalista Gorka Urbizu, es, a día de hoy, uno de los grupos de rock metal más internacionales de la escena vasca. Su música puede definirse como un vehículo para la transmisión de ideas, de alegría, de energía y de intimismo, aderezadas con grandes dosis de rabia y melancolía. Una banda que, en sus directos, bascula constantemente entre melodías cercanas al punk y al hardcore más melódico, y que compositivamente dota a sus letras de una agresividad que sólo está a la altura de su protesta política (Prado, 25-4-2008). Que ha girado por Europa con grupos consagrados en Estados Unidos como Rise Against y que huye del virtuosismo musical porque para ellos «el espíritu y la actitud de la canción es mucho más importante» (Prado, 25-4-2008).

Este leitmotiv les llevó, por ejemplo, a mezclar y masterizar sus discos en Estados Unidos con reconocidos productores discográficos como Ed Rose, Steve Albini y Ross Robinson; profesionales que supieron llegar a la esencia de sus composiciones. Robinson ha sido uno de los más influyentes en la historia reciente de Berri Txarrak, al sacar de ellos un sonido especial y único, fruto del entendimiento y de la admiración mutua a la hora de trabajar. El productor norteamericano, que siempre se ha preocupado por la historia de detrás de las letras, haciendo preguntas personales y profundas para conocer su auténtico significado, y que ha mostrado interés por la idiosincrasia de los grupos y su origen, buscando la autenticidad, ha considerado a Berri Txarrak un combo digno de admiración, sobre todo al 
mantener una trayectoria coherente en la que siempre ha mostrado «su rechazo a cantar en otra lengua que no fuera la suya, a pesar de saber que mucha gente no iba a entenderles» (Sabaté, 08-11-2011).

La banda navarra no hace música para gente feliz, porque no es el tipo de música que se puede encontrar en un anuncio de Estrella Damm. Su sonido es rabioso, melancólico y real, «una pequeña venganza a lo que te rodea» (Prado, 25-4-2008). Así han demostrado, contrapronóstico, que cantar en una lengua minoritaria no es un obstáculo insalvable. De hecho, su música ha sacado definitivamente al euskera del ámbito exclusivamente vasco ${ }^{8}$, demostrando - a su vez - que «la música es algo más amplio y universal que un idioma» (Garayoa, 21-09-2009). En efecto, Berri Txarrak hace música combativa en euskera, sin la pretensión de objetivos de altos vuelos como cambiar el mundo y hacerlo mejor, sino con el interés de «morder un poco [...] agitar y hacer pensar o reflexionar», intentando - empero- acabar con «el petardeo que se da en varios medios musicales» (Garayoa, 21-09-2009).

En sus letras ha denunciado la excesiva presencia de la música de radiofórmula en canciones como SMT (Shitty Music Tavern) y que ha ofrecido su interpretación sobre la situación política reciente en Gure dekadentziaren onenean (En lo mejor de nuestra decadencia): «La política barata sale realmente cara. No se puede decir otra cosa (no digas que no). Si no avanzamos significa que estamos retrocediendo. Mientras no acordamos ninguna meta. No digas que no, no digas que no. Estamos en lo mejor de nuestra decadencia». Un grupo coherente, sincero y honesto con su música9

No obstante, su contenido letrístico ha levantado ampollas en algunos sectores de la derecha española. Aunque sin llegar al extremo de sentar al grupo en el banquillo de la Audiencia Nacional, la Asociación de Víctimas del Terrorismo (AVT) ha arremetido en más de una ocasión contra Berri Txarrak por la temática de sus composiciones. Por ejemplo, con motivo del Hatortxu Rock de 2011, festival musical solidario en el que se reivindica el acercamiento al territorio vasco de los presos allí nacidos y recaudar dinero para que sus familiares puedan sufragar los desplazamientos a los centros penitenciarios, la AVT envió una carta a Pedro Huarte Iribarren, alcalde de Zizur Mayor (localidad del emplazamiento del festival) por NaBai, «solicitándole la suspensión del Festival Hatortxu Rock, ya que se trata de un evento de apoyo a los presos de ETA [...y] su único objetivo es recaudar dinero para los terroristas que cumplen sus condenas en prisión» ${ }^{10}$. A tal efecto, indicó que el cartel es-

\footnotetext{
${ }^{8}$ Las referencias que aquí se realizan son única y exclusivamente referidas a la música rock-metal. Se deja al margen la consabida escena literaria y otros géneros musicales de los que hay sobrada trascendencia allende las fronteras vascas: desde la labor literaria de autores como Kirmen Uribe o Bernardo Atxaga, hasta grupos musicales como Oskorri. También se debe aclarar, para no incurrir en errores y malinterpretaciones desafortunadas, que el uso del euskera como lengua vehicular está completamente constatado en diversos ámbitos como el académico, político, cultural y paradiplomático.

9 «Entrevista a Berri Txarrak», La Rambleta (Valencia), febrero 2015, en www.todopunk.com (canal de YouTube)

10 «La AVT solicitó la suspensión del Festival Hatortxu Rock y no ha obtenido respuesta del Ayuntamiento de Zizur Mayor», 05-01-2011, en http://avt.org/prensa/la-avt-solicito-la-suspension-del-festival-hartortxu-rock-y-noha-obtenido-respuesta-del-ayuntamiento-de-zizur-mayor/518
} 
taba encabezado por Berri Txarrak «una formación que en sus canciones contienen frases que ofenden y atentan contra la Verdad, Memoria, Dignidad y Justicia de las víctimas del terrorismo» ${ }^{11}$.

Para ello, la AVT rescató fragmentos de dos canciones: Adierazi Beharra (Necesito expresar) y Tortura Nonnahi (Tortura en cualquier parte), ambas publicadas en 1997. De la primera, seleccionaron el siguiente fragmento: «El pueblo en el que nací me produce orgullo en el corazón, lo que le debo a la madre de un preso es admiración», aduciendo que era una letra en homenaje a los presos de ETA; pero, como se puede ver, no hace una alusión explícita a los presos de ETA, sino a una experiencia vivencial de carácter puramente subjetivo; de lo único que hace apología es de la admiración que sienten por la sensibilidad y fidelidad de una madre a su hijo, sea o no preso, sea o no culpable, sea o no miembro de ETA ${ }^{12}$.

En el caso de Tortura nonnahi, el extracto escogido por la AVT para denunciar la supuesta cercanía del grupo a ETA era el siguiente: «utilizando la violencia hasta convertir los cuerpos en cadáveres, cogen los presos, los dispersan y los devuelven apaleados. Si matar a un toro en la plaza es cultura, está claro, lo de los españoles es la tortura». Como se puede comprobar, en esta canción centran su discurso en la dispersión de presos e insinúan que la tortura es algo inherente a la cultura española, valiéndose para ello de una alusión a la «fiesta nacional». Por tanto, no demuestra que el grupo enalteciera al terrorismo, como señalaron sus denunciantes, máxime si se valora que en la estrofa posterior manifestaron de forma genérica la existencia de tortura en las cárceles hacia todo tipo de personas por cuestiones de sexo o raza.

Las presiones de la AVT para suspender el Hatortxu no fructificaron, pero los argumentos utilizados para su cancelación pusieron de nuevo sobre la mesa un problema que ya había salpicado a Berri Txarrak, valiéndole su inclusión en el sector demonizado por la derecha y los medios de comunicación dentro de esta onda: el entorno de ETA. Su postura ideológicamente cercana a la izquierda abertzale, sumado a su participación en las iniciativas solidarias a favor de los grupos vascos perseguidos por la derecha política, les situó dentro de una - no reconocida por la AVT - lista negra de grupos musicales non gratos en la que ya estaba Soziedad Alkoholika y Fermín Muguruza. Una lista que, pese a ser negada a la mayor por la propia AVT, el PP y, en general, las instituciones controladas por este, es una obviedad, como ha señalado el activista político Juan Ibarrondo en una entrevista:

Creo que hay una lista negra. Es bastante evidente, no, entre los ayuntamientos de cierto color político, yo creo fundamentalmente del Partido Popular. Tampoco conozco el tema al detalle, eh. Pero si parece bastante evidente, porque hay a grupos

\footnotetext{
11 Ibid.

${ }^{12}$ Las interpretaciones pueden ser muy variopintas, porque, siguiendo la interpretación realizada por Maider Galardi Fernández de Aguirre sobre las canciones revolucionarias populares vascas, se podría valorar el fragmento de esta letra desde una perspectiva de admiración por la mujer vasca, por la madre de los gudaris de la patria e incluso por el matriarcado. Una interpretación (en realidad, una hipótesis) que sólo es plausible si se tiene en cuenta el bagaje cultural y folclorista de los integrantes de Berri Txarrak (Galardi, 2012: 10-11).
} 
que sistemáticamente no se les programa, a pesar de que haya en las comisiones de fiestas de pueblos o de barrios, se intenta que vengan, que vayan a tocar a sus localidades y siempre hay ese veto, no, y siempre es el mismo partido político. Eso es una lista negra. Pues yo pienso que sí. La hay, que circulará entre ellos. Me parece una obviedad $^{13}$.

Pero volviendo a Berri Txarrak. En enero de 2004, la sala Caracol de Madrid tuvo que suspender el concierto de Berri Txarrak, porque los propietarios no pudieron garantizar la seguridad de los artistas ni del público, ante las presiones de «un grupo de provocadores violento [que] había anunciado su aparición en el espectáculo, debido a las letras del conjunto, que hacen referencia a la dispersión de presos etarras y hablan de torturas» ${ }^{14}$. Aun así, la AVT ni atendió a este tipo de amenazas, ni reparó en su actividad de seguir intentado bloquear sus conciertos, porque en sus canciones «insultaba» a los españoles llamándoles «subnormales». De nuevo, sostenía sus afirmaciones con información errónea o, por lo menos, sin estar apropiadamente contextualizada. Para ellos, la canción Onak eta Txarrak (Los buenos y los malos) era prueba de esta evidencia, pero, en realidad, esta letra había sido realizada, precisamente, para denunciar a los intolerantes que perseguían a la música underground vasca. Lo más curioso de todo es que en la canción no había referencia directa a España o a los españoles en ningún momento. Estos son algunos extractos que podrían considerarse controvertidos:

una vez vinieron los subnormales a cuidar al normal. Una vez vinieron los subnormales a manifestarse señalando a los buenos y a los malos en el nombre del bienestar. Una vez vinieron los subnormales con el sentido en los dientes. Una vez vinieron los subnormales a poner orden. Señalando a los buenos y a los malos, siempre a sus órdenes. [...] El que no sabe hablar hace ruido sin argumento. [...] estamos vivos y empezándonos a enfadar.

Dentro de la amalgama de desinformación, medios de comunicación y prensa de la línea editorial de $A B C$ hicieron un uso reiterado de estereotipos y etiquetas muy manidas para definir a los grupos vascos. Así, por ejemplo, Berri Txarrak y Fermín Muguruza fueron descritos como combos "partidarios en ocasiones de la violencia en el País Vasco»" ${ }^{15}$. Nada más lejos de la realidad, si se tiene en cuenta que Muguruza condenó ya en el año 2000 el asesinato del teniente coronel Pedro Antonio Blanco a manos de ETA. Pero, no importó.

En 2009, el suplemento dominical de $A B C$ publicó un artículo sobre el aumento del número de organizaciones nacionalistas radicales en Galicia que tenían a la lengua vernácula en el centro de su discurso. En este se señaló que el grupo juvenil Agir había actuado violenta y agresivamente en las calles de Santiago de Compostela, tras conocer la decisión del edil del área de seguridad ciudadana Carlos Nieves de suspender un concierto de Berri

\footnotetext{
13 Entrevista realizada por el autor a Juan Ibarrondo.

14 «La sala Caracol suspende el concierto de Berri Txarrak», $A B C, 10-01-2004$, p. 39.

15 «Un polémico boicot», $A B C, 16-10-2004$, p. 87.
} 
Txarrak e Inadaptats. El edil había considerado inoportuno contar con la participación de un grupo que llamaba torturadores a los españoles ${ }^{16}$. En abril de ese mismo año, el Partido Socialista Gallego había censurado un concierto de Soziedad Alkoholika bajo los mismos argumentos. A la vista de la lectura de los artículos publicados al respecto por $A B C, L a R a-$ zón y El Mundo, entre otros, se observa que los periodistas responsabilizaron, de algún modo, a los grupos musicales de las acciones violentas, como si el contenido de sus letras hubiese sido el detonante de las mismas.

En septiembre de 2010, ante la celebración del festival En Vivo de Getafe, el periodista José M. Camarero se hizo eco de unas declaraciones de Carlos González, portavoz municipal del PP, en las que describió la participación de Berri Txarrak, Sutagar y Soziedad Alkoholika como un acto infame: «un macrofestival con las mayores estrellas del rock nacional [...] puede convertirse en un evento en el que se humille a las víctimas del terrorismo» (Camarero, 28-09-2010). La presión del partido de la oposición llevó a que Pedro Castro, alcalde de Getafe por el PSOE, asegurara ante los medios que había dado instrucciones a los organizadores para que las bandas vascas no interpretaran canciones pro-etarras. No obstante, si así fuera el caso, continuó, la organización sería la principal responsable, porque el Ayuntamiento había contraído un compromiso «con las víctimas del terrorismo, como miembro del Foro de Ermua» ${ }^{17}$.

Más duros y torticeros fueron los argumentos de La Razón. En julio de 2011, este diario publicó - con motivo del cambio realizado por EH Bildu en el cartel de los conciertos de las fiestas estivales de Donostia-San Sebastián (sustitución de La Mala Rodríguez y Melocos por Berri Txarrak y Sutagar) - que el objetivo era volver a tomar la calle «para recuperar el tiempo perdido, cuando la legislación vigente se aplicaba con todo rigor y no se permitían las actuaciones de los proetarras» (Zuloaga, 26-7-2011). El periodista de La Razón Jesús María Zuloaga consideró que la afinidad de Berri Txarrak con el entramado de ETA era evidente, pues Gorka Urbizu había sido imputado en 2009 «por un delito de colaboración con banda armada por apoyar a Gaztasarea [sic.]» (Zuloaga, 26-7-2009).

Olvidaba Zuloaga que el cantante de Berri Txarrak había sido absuelto sin cargos por Fernando Andreu, magistrado titular del Juzgado Central de Instrucción número 4 de la Audiencia Nacional y que la Fiscalía del mencionado tribunal no había solicitado ningún tipo de medida cautelar contra él. Las evidencias eran insuficientes. No podían inculparle señalando que apoyaba a ETA, cuando la acusación había sido incapaz de demostrar que Urbizu hubiera comprado, como aducían en la denuncia, bonos de financiación a ETA en el portal de internet Gaztesarea, que gestionaba la organización juvenil de izquierda abertzale Segi ${ }^{18}$.

\footnotetext{
16 «Individuo joven y encapuchado que aprovecha las aglomeraciones», La Voz de Galicia, 11-04-2003, en http:// www.lavozdegalicia.es/galicia/2003/04/11/0003_1607028.htm

${ }^{17}$ Ibid.

18 «El juez Andreu deja en libertad a tres jóvenes vinculados con la página Gaztesarea.net», El Correo, 07-09-2009, en http://www.elcorreo.com/alava/20090907/mas-actualidad/politica/juez-andreu-mantieneimputados-200909071707.html
} 
Zuloaga insistió. La orientación pro-terrorista de los grupos que copaban de nuevo los escenarios vascos era evidente porque, por ejemplo, Aitor Gorosabel, cantante y guitarrista de Sutagar, había compuesto «Bildu gara bildu», canción que había utilizado la coalición política para su campaña electoral. Pero, omitía de nuevo que en ella también habían participado destacadas personalidades de la cultura vasca, vinculados o no con la izquierda abertzale, como la bertsolari Miren Amuriza, el actor Ramón Agirre, la actriz Itziar Ituño, el payaso José Mari Agirretxe (Porrotx), el pintor «Mendi», el músico Imanol Urbieta, el bertsolari Jon Maia, el músico «Txapas», el escritor Gari Berasaluze y el bertsolari Jon Martin $^{19}$. Evidentemente, EH Bildu como otros partidos de la izquierda abertzale tiene un pasado vinculado a una época difícil, convulsa y violenta, en la que algunos de sus líderes formaron parte del entramado político y militar de la mencionada organización terrorista $^{20}$, pero ¿por qué esta doble moral y este doble rasero a la hora de valorar lo sucedido? ¿por qué esta polarización política, social y cultural? ¿por qué este ensañamiento contra la música underground vasca?

Sea como fuere, en el horizonte de la política de criminalización de la derecha todo valía; pues estaban buscando el respaldo necesario para intentar apartar a todo aquel elemento disidente que pudiera contravenir a los intereses de la cultura dominante y, de paso, extender la sombra de ETA sobre la contracultura vasca. En este artículo, que fue lo más similar a una cruzada particular contra el grupo navarro, Zuloaga señaló que de sobra eran conocidas «las letras de Berri Txarrak en las que se incita a la rabia hacia el Estado opresor español, se tacha a los españoles de subnormales y fascistas de mierda y se describe a los ciudadanos vascos como torturados que buscan liberar a la patria vasca» (Zuloaga, 267-2009). Pero, ¿por qué molestaba tanto al periodista que los músicos vascos hablaran de la tortura? ¿Acaso ponía sobre la mesa las dificultades inherentes a una versión única del relato sobre la violencia terrorista?

En parte, con esta actitud, Zuloaga corroboraba lo que Edurne Portela ha denominado como «la fuerza con la que el fanatismo se apropia del lenguaje» (Portela, 2016: 65). En definitiva, una agresividad que «aísla a los «no fanáticos» a mantenerse en silencio» (Portela, 2016: 65). En este sentido, no deja de resultar llamativo que, años antes, Loquillo fuera censurado por hablar de la tortura policial en una de sus canciones. En 1993, publicó «Los ojos vendados», una canción cuyo vídeo musical causó bastante polémica, porque se veía a un joven vasco que había sido arrestado por error y torturado para obtener información. En realidad, el videoclip, dirigido por Aitor Zabaleta, había sido utilizado para transmitir un mensaje de Amnistía Internacional, que consideraba que había poca transparencia y claridad en las investigaciones sobre la tortura en España. Estas críticas a los métodos de

\footnotetext{
19 «Un grupo de personas de la cultura vasca crea una canción de apoyo a Bildu», El Mundo, 19-04-2011, en http://www.elmundo.es/elmundo/2011/04/19/paisvasco/1303216093.html

20 A grandes rasgos se tiende a pensar que EH Bildu es la mera evolución de Herri Batasuna y, aunque pueda parecer así, visto en perspectiva debe valorarse que es una coalición política compuesta por un heterogéneo número de partidos de izquierda abertzale, con diferentes matices y procedencias, como Aralar, Eusko Alkartasuna, Ezker Anitza o Alternatiba.
} 
la policía no fueron bien acogidas por el establishment, que presionó a las emisoras de radio para que vetaran la canción, obligando a Loquillo a elegir otro single para promocionar el disco Mientras respiremos. En declaraciones a El País, el cantante barcelonés manifestó la existencia de un boicot hacia su canción, porque «es una canción basada en hechos reales sucedidos en Euskadi; lo que no me imaginaba era este busca y captura contra la canción» ${ }^{21}$. Loquillo se sintió ultrajado ante las excusas expuestas por las emisoras que habían decidido no hacerla sonar, porque era «un tema malo y triste», razón por la que el cantante estaba sumamente enfadado como "artista antifascista». También, aseguró que «oficialmente no existe la censura, aunque sí existe envuelta en otros sistemas porque yo no sé qué voy a tener que cantar la próxima vez» (Alonso, 3-09-1993). Como ha señalado Juan Albarrán, si en la década de 1990 la visibilización de la tortura era perseguida sistemáticamente, incluso en un videoclip aparentemente inofensivo y avalado por una ONG, no resulta extraño que en la época del «todo es ETA» se persiguiera con más ferocidad, si cabe, a grupos underground como Berri Txarrak que habían denunciado este hecho sin ambages (Albarrán, 2014: 26).

El grupo navarro tenía en su contra una especie de inercia aséptica que engullía todos los espacios y que perseguía a la música contestataria. Años antes, el grupo había expresado su sentimiento de estar en el punto de mira de los políticos y la prensa conservadora en Arren Darwish (Payola, 2009): «Puede que escondan su verdadera opinión detrás del muro que han levantado con palabras. Siento el puñetazo de la vergüenza ajena, una rabia descomunal». Sabían que parte de esta situación eran consecuencias, daños colaterales causados por su carácter. En Albo Kalteak (Haria, 2011) así lo indicaron: «Estos son, cómo decirlo, los daños colaterales de ser nosotros mismos las consecuencias del no-ser. A toda esa dialéctica del menosprecio: eppur si muove. A esa ley hecha a conveniencia: si muove. A todo aquel que tiene que pisar al prójimo para ser alguien váyanle estas palabras desde estos acordes eppur si muove». Las críticas recibidas sólo servían para reiterar al grupo que su camino era el correcto, porque si el rock «pierde ese punto de peligro, [...] deja de interesar. El elemento punk y la actitud de provocar es básica. Como también lo es aprovechar el altavoz que tenemos para decir cosas que inviten a la reflexión» (Sabaté, 8-11-2011).

Aunque han mantenido una línea crítica, la autocensura es patente, como se comprueba en Denbora da poligrafo bakarra (el tiempo es el único polígrafo). En noviembre de 2014, Berri Txarrak confirmó en declaraciones para Mondo Sonoro su intento de evitar ciertas controversias con sus composiciones: «Hay que buscarle la vuelta, con lo que no es tan fácil y corres el peligro de hacer letras demasiado crípticas. Por eso, hacer hoy en día una buena canción punk con una letra como las de Eskorbuto es muy complicado» (Hagen, 2911-2014). Estas declaraciones traen a colación la cuestión del cambio de perspectiva en los músicos (el de la obligada evolución por presiones discográficas y mediáticas o por una transformación de pensamiento) y de la libre creación artística y de expresión; de ellas

21 «Loquillo afirma que las emisoras censuran su canción sobre las torturas», El País, 11-12-1993, http://elpais. com/diario/1993/12/11/cultura/755564403_850215.html 
se infiere que, con una democracia más consolidada pero también con un Estado de derecho más exigente, resulta más complicado publicar una canción con un contenido plenamente transgresor, como pudo ser cualquiera del disco de Anti-todo de Eskorbuto. Corren el riesgo de ser censurados ante el dominio que ejerce lo políticamente correcto sobre el espectro de lo público (Martínez, 2006; Barraycoa, 2001: 51-61). ¿Qué ha cambiado? ¿Hasta qué punto la legislación, las instituciones, los partidos políticos y los grupos de presión han obtenido poder cómo para copar con lo políticamente correcto espacios contraculturales como el de la música underground?

Berri Txarrak, como muchas otras bandas de música underground estatales, ha sido uno de los afectados por esta nueva forma de discurrir de la sociedad actual. Una sociedad dominada por la pasión censora que reprime a todo aquel que se salga de la norma; en la que, fruto del bombardeo mediático, sale a relucir el policía que todos llevamos dentro, enjuiciando hechos sobre la base de estereotipos (Pennisi y Cangi, 2016). Slavoj Zizek ha sido claro en este punto, se trata de un discurso populista conservador cuyo poder y eficiencia siempre ha dependido de la influencia que tuviera el mecanismo autocensor sobre las personas a las que se quisiera silenciar. De este modo, los discursos radicales y subversivos, habitualmente censurados por el establishment, han mejorado de forma indirecta la eficiencia del discurso del poder, como se ha podido comprobar en la asunción por parte del artista de un nada desdeñable grado de autocensura (Zizek, 2011: 35). Por tanto, en una sociedad en la que hay establecidos una serie de límites que determinan qué conductas y posicionamientos socio-políticos son (o no) legítimos para sus integrantes, cualquier anomalía que pueda ser nociva ha de eliminarse física y simbólicamente (Edelman, 1985: 22 y ss.) $)^{22}$.

Las vías utilizadas por el poder, por tanto, pueden ser muy variadas, sibilinas, pero habitualmente recurren a la caricaturización. En enero de 2015, Berri Txarrak afirmó en Mondo Sonoro que se había visto afectado por esta estrategia, pues se habían dicho cosas del grupo sin conocerlo demasiado "por prejuicio o peores bajezas» ${ }^{23}$. Valorando positivamente que la época más oscura se hubiera apaciguado, veían difícil que la situación pudiera estabilizarse: la cultura crítica siempre ha molestado a los poderosos a quienes «no interesa que haya grupos que cuestionen las cosas» (Ochoa, 4-02-2015). Pero, los que ejercen el poder siempre han necesitado de los subversivos y viceversa, porque es su manera de legitimarse mutuamente: «sin ley no hay transgresión, y la transgresión necesita un límite para afirmarse» (Zizek, 2011: 36).

Así, las celebraciones de conciertos reivindicativos, subversivos, si cabe, han situado casi siempre a la música underground en el ojo del huracán. En septiembre de ese mismo año le volvió a tocar a Berri Txarrak. Su participación en un macro-concierto que había orga-

\footnotetext{
22 Estas cuestiones las ha explicado de manera sucinta Gorka Romero (Romero, 10-5-2018).

${ }^{23}$ «No Confidencial», Mondo Sonoro, 8-01-2015, http://www.mondosonoro.com/entrevistas/berri-txarrak-noconfidencial/
} 
nizado la plataforma anti-OTAN de Zaragoza contra las maniobras Trident Juncture, junto a Siniestro Total, Habeas Corpus, Def Con Dos, Irregular Roots y Nacho Vegas, levantó gran revuelo mediático ${ }^{24}$. La AVT y el portavoz adjunto del PP del Ayuntamiento de Zaragoza, Jorge Azcón, solicitaron que el consistorio municipal impidiera la presencia del grupo navarro en el evento, porque su contenido letrístico enaltecía al terrorismo. La AVT lo manifestó en su web del siguiente modo:

La Asociación Víctimas del Terrorismo (AVT) ha solicitado a través de una carta dirigida al alcalde de Zaragoza, Pedro Santiesteve, la cancelación de la actuación que el próximo 25 de septiembre ofrecerá el grupo proetarra Berri Txarrak en el Auditorio Municipal de la ciudad maña dentro del concierto organizado por la Plataforma Anti-OTAN de Zaragoza. En la misiva, firmada por Ángeles Pedraza, la AVT recuerda al alcalde zaragozano que el grupo navarro enaltece con las letras de sus canciones la actividad de la banda terrorista, algo que supone «un desprecio total y absoluto» hacia las víctimas a las que ETA arrebató la vida. La AVT, que destaca en la carta su más absoluta "repulsa» hacia las letras del grupo, recuerda a Pedro Santiesteve que el Ayuntamiento que él preside «tiene la potestad para impedir» la actuación de Berri Txarrak y se muestra confiada en que la Corporación Municipal acoja «favorablemente» la petición realizada desde la asociación para salvaguardar la memoria y la dignidad de las víctimas del terrorismo ${ }^{25}$.

Según se ha apuntado en algunas fuentes, con esta denuncia, el PP buscaba dañar la imagen del recién constituido gobierno municipal de Zaragoza en Común vinculándoles con el entorno de ETA. La aparición de partidos políticos como Podemos, que han gozado de un apoyo creciente en la juventud, ha provocado que la derecha haya multiplicado sus esfuerzos para deslegitimarles. Rosa Díez ya señaló a Podemos en este sentido y Esperanza Aguirre indicó sin paliativos que «Podemos está con el chavismo, con el castrismo y con ETA $»^{26}$. Han explotado, pues, cualquier tipo de argumento - por mínimo que sea-contra la coalición morada y sus confluencias, siendo en este caso la creación musical, la libertad de expresión y las víctimas del terrorismo las utilizadas como pretexto para situar a los grupos musicales en el centro del debate. En este caso, además de pedir que el concierto de Berri Txarrak fuera vetado, el PP y la AVT exigieron al Ayuntamiento de Zaragoza que declarara a los miembros del grupo personas non gratas. Entonces, los medios de comunicación de la denominada caverna mediática sacaron a relucir sus recursos más abyectos. Antonio Jiménez, polémico conductor del programa El Cascabel, de 13TV, manifestó

\footnotetext{
24 «El PP pide vetar a Berri Txarrak en Zaragoza por enaltecimiento al terrorismo», Mondo Sonoro, 1009-2015, http://www.mondosonoro.com/noticias-actualidad-musical/pp-berri-txarrak-enaltecimiento-alterrorismo/. Véase también: «Siniestro Total y Berri Txarrak contra la OTAN en Zaragoza», El Periódico de Aragón, 18-09-2015, en http://www.elperiodicodearagon.com/noticias/aragon/siniestro-total-berri-txarrak-otanzaragoza_1054013.html

${ }^{25}$ «La AVT pide al alcalde de Zaragoza la suspensión del concierto del grupo proetarra Berri Txarrak», 1109-2015, en http://avt.org/prensa/la-avt-pide-al-alcalde-de-zaragoza-la-suspension-del-concierto-del-grupoproetarra-berri-txarrak/1218

${ }^{26}$ "Aguirre vuelve a ligar a Podemos «con el castrismo, el chavismo y ETA» tras el archivo de la causa contra ella», Eldiario.es, 30-07-2015, en http://www.eldiario.es/politica/Aguirre-Podemos-castrismo-chavismoETA_0_414708913.html
} 
sin ambages que las ideas de izquierda, las letras críticas con el sistema y la procedencia territorial eran signos evidentes de que los grupos musicales como Berri Txarrak eran pro-etarras:

Ha generado cierta indignación, por lo menos en un amplio sector de la ciudadanía de Zaragoza, que es una ciudad como ustedes saben, y si nos están viendo desde Zaragoza, en fin, qué voy a decirles yo; una ciudad que fue en algunos momentos de los años de plomo muy castigada por el terror de ETA. Ahí murió un secretario general del Partido Popular, Jiménez Abad. Ahí murieron en un atentado contra la casa-cuartel de la Guardia Civil, yo no recuerdo cuantos, pero más de once probablemente. No recuerdo ahora bien, pero, en fin, no quiero equivocarme. Ciudad castigada por el terror de ETA, con muertos y heridos. Bueno, pues este alcalde, el alcalde podemita de Zaragoza, señor Santisteve, ha decidido darle cobertura a un conjunto musical pro-etarra porque así lo ha decidido su alegre y combativo carácter (Jiménez, 9-9-2015).

Los tertulianos de este programa no se detuvieron ahí. Teresa Fernández, periodista de este canal, realizó un reportaje con imágenes del atentado de ETA de 1987 en Zaragoza, asociando directamente este suceso con la decisión de Santisteve de permitir la celebración del concierto anti-OTAN en el que participaba Berri Txarrak; como si el primer edil zaragozano estuviera dando vía libre a algún tipo de acto terrorista. Con una música inquietante de fondo, la voz superpuesta de Fernández decía lo siguiente:

Este alcalde podemita ha tenido la brillante idea de autorizar un concierto contra la OTAN en el que participarán entre otros, el grupo navarro pro-etarra Berri Txarrak, que ensalza a los presos de ETA e insulta a la policía; el grupo Berri Txarrak canta en euskera y ha sido denunciado en numerosas ocasiones por las víctimas del terrorismo por enaltecimiento del mismo y por mostrar su apoyo a los presos etarras, tanto en sus letras como en sus actuaciones, algunas de las cuales llegaron a ser suspendidas (Jiménez, 9-9-2015).

De las palabras vertidas por esta periodista tan sólo se salvaba el hecho de que Berri Txarrak había sido denunciado por la AVT. Una denuncia que, como se ha visto, fue realizada en 2009 sobre la base de que este grupo musical realizaba apología del terrorismo con las letras de sus canciones y, por ello, había solicitado la cancelación de uno de sus conciertos. Una suspensión que, por otro lado, nunca llegó a producirse porque la institución judicial correspondiente desestimó la denuncia. Sin embargo, ambos periodistas omitieron este hecho, posiblemente, porque su objetivo era ofrecer una interpretación acorde a su ideología e intencionalidad política. Se trató de una manipulación mediática que quería aprovechar la participación de un grupo vasco para estigmatizar a la música underground. En definitiva, de una batalla más de la guerra cultural a la que está siendo sometida la contraculturalidad, en la que se están imponiendo líneas rojas que no sólo merman la libertad de expresión, sino que provocan un choque de sensibilidades y de visiones del mundo antagónicas (Soto Ivars, 2016). 
Con todo, la respuesta de los navarros no se hizo esperar y el 10 de septiembre publicaron el siguiente comunicado:

Lamentamos y denunciamos este nuevo intento de censura que representa un ataque al Derecho Fundamental de la Libertad de Expresión que siempre hemos defendido y seguiremos defendiendo con nuestras canciones. Berri Txarrak jamás ha recibido denuncia, imputación o condena formal alguna en más de dos décadas de carrera, por lo que las prácticas que se nos atribuyen en varios medios carecen de base jurídica; más bien responden a un plan de criminalización a mayor escala que lamentablemente se está alargando demasiado en el tiempo y afecta a más artistas. Asimismo, denunciamos el uso interesado que se pueda hacer de nuestro nombre para atacar a terceros (véase partidos políticos o asociaciones), en lo que entendemos una clara estrategia electoralista de la cual nos desmarcamos y tras la cual se esconde el ala más reaccionaria del espectro político. No estamos dispuestos a ser la marioneta política de una guerra que no es la nuestra. Basta con recordar que en el último año hemos actuado en multitud de municipios gobernados por el PP, además de haber sido invitados a actuar en RTVE (con excelente audiencia, por cierto $)^{27}$.

Con esta declaración, Berri Txarrak se desmarcó de cualquier tipo de polémica, destacando que no tenían ninguna causa pendiente con la justicia y que les resultaba verdaderamente lamentable la manipulación de la música underground con fines electoralistas. Además, recordaban, que la estrategia del PP carecía de coherencia, si se tenía en cuenta que habían actuado en la televisión pública española y que les habían contratado en diferentes municipios gobernados por el mencionado partido político. Por tanto, consideraban que no había ningún argumento sólido contra ellos y que seguirían adelante con la actuación. Así, describió Gorka Urbizu la postura de su banda:

Berri ha sido censurado varias veces y por eso no puedo decir que sea una nueva censura. Creo que es antigua. También quiero pensar que da sus últimos coletazos, no sé cómo decirlo, o eso es lo que creo o lo que quiero [...] En todo caso me parece grave, me parece ridículo y me parece también un poco un síntoma de cómo se trata a la cultura. Se banaliza mucho. No hay más que ver los medios, como se aparta el rock y todo lo que se salga un poco de lo standard o de lo no peligroso [...] Tampoco creo que haya que hacerle demasiado caso a eso y hay que seguir adelante y seguir haciendo canciones y hacer lo que uno cree. Me parece muy chabacano en el fondo, no lo quiero dar tanta importancia, me parece grave, me pone de la mala hostia, pero la vez me parece tan cutre y tan poco sólido que creo que no hay que darle mucha $\mathrm{coba}^{28}$.

27 Comunicado de Berri Txarrak http://www.berritxarrak.net/berri-txarrak-taldearen-adierazpena/?lang=es

28 «Entrevista a Gorka Urbizu», Rockpills TV (51), 3-6-2015, www.youtube.com/watch?v=kVH58w5Qf5o 


\section{A MODO DE CONCLUSIÓN: EN LOS LÍMITES DE LA LIBERTAD DE EXPRESIÓN}

El establishment tiene un único objetivo: hacer que su opinión se convierta en un axioma, un factor más de la vida con el que construir una mentalidad común en la que todo lo que se salga de su constreñimiento pueda ser atacado, señalado y apartado. Pero, no es una excepcionalidad española, sino más bien al contrario, porque lo hasta aquí descrito, no es un proceso novedoso. En Francia, por ejemplo, en julio de 2015, saltó la polémica cuando Vicent Bolloré, propietario de Canal Plus Francia e íntimo amigo del conservador Nicolás Sarkozy, propuso acabar con los guiñoles, uno de los programas más críticos de la televisión francesa, porque quería «deshacerse de estos incómodos bufones» (Teruel, 5-7-2015). Bolloré no contó con que este programa fuera muy valorado por la sociedad francesa, que incluso lo consideraba una necesidad, porque ayudaba a despertar conciencias críticas con la política de su país. En efecto, los problemas relativos al uso de una plena libertad de expresión, están generando controversias en la mayoría de países gobernados por partidos conservadores. Pero, y he ahí donde radica la diferencia entre lo ocurrido en España y otros países, mientras aquí se condenó a prisión preventiva a unos simples titiriteros, que nadie conocía y cuyo impacto era ínfimo, por ironizar acerca de la inculpación policial; en Francia, el presidente Hollande y el primer ministro Valls, así como el actor Jean Dujardin, salieron en defensa de estos irreverentes muñecos de humor ácido, consiguiendo evitar la pérdida de un "patrimonio de la televisión francesa» (Teruel, 5-7-2015). En definitiva, como ha señalado César Strawberry, cantante de Def Con Dos, también imputado en el marco de la ley mordaza, la libertad de expresión en España atraviesa un momento muy contradictorio e injusto:

A nivel de libertad de expresión se actúa con un doble rasero vamos, que reconoce cualquiera. La justicia está muy politizada, está a unos niveles que causan estupor. Y no se tratan igual los comentarios de determinadas personas que pueden estar más próximas a la derecha, que de determinadas personas que pueden ser proclives a opiniones ideológicas de izquierdas. En ese sentido, creo que hay ahí un sesgo claro a favor de los derechistas en el sentido de que cuando un concejal de un pueblo de Palencia dice que hay que ejecutar a Pablo Iglesias, darle un tiro y dejarlo tirado en una cuneta nadie considera que, ninguna autoridad judicial considera que eso sea una amenaza a tomar en serio ${ }^{29}$.

Ante situaciones como las experimentadas por Berri Txarrak, César Strawberry, Soziedad Alkoholika o Fermín Muguruza, todas ellas acaecidas en plena democracia, resulta irremediable establecer comparaciones. Si durante la Transición el pueblo recuperó la calle, se adueñó de los espacios públicos y las instituciones comenzaron a valorar sus manifestaciones; si todo ello redundó, aunque fuera por mero interés electoralista, en una democratización de los espacios públicos, permitiendo la celebración de conciertos, festivales y, en

${ }^{29}$ Entrevista a César Strawberry realizada por el autor, 20-06-2016. 
general, una dinamización de la cultura española ¿por qué ahora (en pleno 2018) se persigue a grupos de música y personas del ámbito de la cultura que simplemente reclaman su espacio? ¿Estamos asistiendo a un proceso de involución cultural en la que lo reaccionario y contestatario es automáticamente demonizado? ¿Por qué se busca homogeneizar la cultura española cuando en la diversidad está la riqueza de matices?

En los últimos años, bandas como las destacadas y otras como Valtonyc, La Insurgencia, Los Chikos del Maíz, Pablo Hásel o los famosos titiriteros han sido denunciados por enaltecimiento del terrorismo, insultos a la corona o por ofensas contra la religión. En este país se ha entrado en una dinámica en la que ya no sólo se sospecha de los grupos vascos quienes, según la lógica de los medios de comunicación y partidos de derechas, por su procedencia tienen algún tipo de vinculación con el terrorismo y la izquierda abertzale. Todo grupo músico-artístico, normalmente situado en la órbita de la izquierda, que mantiene una opinión distinta a la oficial es, a día de hoy, en el mejor de los casos, considerado un simple excéntrico y, en el peor, un elemento marginal extremista a erradicar. El establishment tiene un único objetivo: hacer que su opinión se convierta en un axioma, un factor más de la vida con el que construir una mentalidad común en la que todo lo que se salga de su constreñimiento pueda ser atacado, señalado y apartado ${ }^{30}$. En buena manera, se está produciendo, como ha señalado Gorka Romero, en la línea de Edelman y Filibi, un conflicto profundo entre juego y dogma, cuyo discernimiento queda sujeto tanto a su significado ideológico y/o simbólico como a la amenaza que suponga para el establishment (Romero, 10-5-2018). Estos desafíos son, cuando menos, peligrosos, porque, ante la ley, la relativización y el desequilibrio deben evitarse, y, a la vista de la trayectoria de grupos como el aquí analizado, la salud de lo alternativo, de lo undeground y lo contracultural queda en entredicho, sobre todo, cuando el simple juicio de cualquier medio de comunicación sobre un determinado acto y/o posicionamiento es ya la condena definitiva (Soto Ivars, 2016).

No es baladí, por tanto, que, tras las manifestaciones de protesta producidas ante la situación de crisis incontenible (movimiento 15-M y posteriores), que fueron el catalizador del renacimiento de la música política, quienes preconizaron el final de este desvencijado sistema político, surgido tras la muerte de Franco, hayan atado cabos y, bajo su perspectiva política, hayan establecido nexos entre el agónico tardofranquismo y la crisis del régimen democrático constituido en 1978 (Simón, 9-12-2012).

\section{BIBLIOGRAFÍA}

Abril, G. (14-06-2016): «Confidencias. Mi vida en 10 canciones. Patxi López», El País Semanal, http://elpaissemanal.elpais.com/confidencias/patxi-lopez/

${ }^{30}$ Jones, 2015: 16. 
Albarrán, J. (2014): «Violencia política y visualidad: sobre la representación de la tortura en democracia», Tiempo Presente: Revista de Historia, n. ${ }^{\circ} 2$.

Alonso Olea, E. (2002): «Evolución económica, 1977-2002», en Jaime Fernández Alcedo (dir.): De la crisis a la globalización. XXV últimos años del metal de Bizkaia, Bilbao, FVEM, 20-49.

Alonso, A. (03-09-1993): "Censurado un vídeo de Loquillo por tratar el tema de las torturas», El Mundo.

Álvarez, J.C. (2013): «Las publicaciones underground en España: pasado, presente y futuro de un modo de diagnostica la realidad», en M.J. Miranda et al. (eds.): Filosofías subterráneas. Topografías. XLVIII Congreso de Filosofía Joven, Madrid, Plaza y Valdés.

Amo, I. (2016): Party \& Borroka. Jóvenes, músicas y conflictos en Euskal Herria, Tafalla, Txalaparta.

Arriola, J. (2016): A los pies del caballo. Narcotráfico, heroína y contrainsurgencia en Euskal Herria, Tafalla, Txalaparta.

Atutxa, I. (2014): Sabotajes de la cultura vasca. Acerca de la nación encima del canón y haca una nación-otra bajo tachadura, Valencia, Universitat de Valencia

Bassets, L. (2013): El último que apague la luz: sobre la extinción del periodismo, Madrid, Taurus.

Beorlegui, D. (2017): Transición y melancolía: la experiencia del desencanto en el País Vasco (1976-1986), Madrid, Postmetrópolis Editorial.

Burutxaga, S. (2015): "Y no había playa bajo los adoquines. Memoria de la Transición cultural», en M. Toral (ed.): La calle es nuestra. La Transición en el País Vasco 19731982, Bilbao, Kultura Abierta, 2015.

Camarero, J.M. (28-09-2010): «El PP exige en Getafe anular un concierto con grupos proetarras", $A B C$, p. 53.

Dávila, P. y Amézaga, J. (2003-2004): «Juventud, identidad y cultura: el Rock Radical Vasco en la década de los 80», Historia de la educación (22-23), 213-231.

Della Porta, D. y Diani, M. (2006): Los movimientos sociales, Madrid, Editorial ComplutenseCIS.

Edelman, M. J. (1985): The Symbolic Uses of Politics, Chicago, University of Illinois Press. 
Escribano, M. (24-03-2016): «La Raíz: la ley mordaza trata de enjaular el arte y la libertad de expresión», InfoLibre: información libre e independiente, en http://www. infolibre.es/noticias/cultura/2016/03/21/la_raiz_quot_ley_mordaza_trata_enjaular_ arte_libertad_expresion_quot_46647_1026.html

Fernández G. (2015): La voluntad del gudari. Génesis y metástasis de la violencia de ETA, Madrid, Tecnos.

Fernández, G. (2015): «Introducción», en M. Toral (ed.): La calle es nuestra. La Transición en el País Vasco 1973-1982, Bilbao, Kultura Abierta.

Ferrándiz, F. y Feixa, C. (2005): Jóvenes sin tregua. Culturas y políticas de la violencia, Barcelona, Anthropos.

Figuet, C. y Simón, P. (12-04-2016): «El PSOE no deja de ser la primera organización de los indignados de este país», JotDown Contemporary Cultur Magazine, en http://www. jotdown.es/2016/04/patxi-lopez/

Freud, S. (1966): El malestar en la cultura, Madrid, Alianza.

Galardi, M. (2012): «Sexismo en las canciones revolucionarias populares vascas de 19701980", Actas del XII Congreso Español de Sociología: grandes transformaciones sociales, nuevos desafíos para la sociología, 30 de junio, 1 y 2 de julio de 2016, Laboral, Ciudad de la cultura (Gijón).

Garayoa, F. (21-09-2009): «Berri Txarrak», Diario de Noticias de Navarra, en http://www. manerasdevivir.com/entrevista-berri-txarrak-200909.php

García Herrera, R. et al. (1990): Ciudades saludables: margen izquierda, Vitoria Gasteiz, Gobierno Vasco.

García Salueña, E. (2013): «El rock español desde sus inicios hasta la experimentación progresiva», en K. Mora y E. Viñuela: Rock around Spain. Historia, industria, escenas y medios de comunicación, Lleida, Edicions de la Universitat de Lleida.

Guadilla, D. (03-10-2011): «López nombró a Joseba Sarrionaindia en la toma de posesión del cargo de lehendakari», El Correo, en http://www.elcorreo.com/vizcaya/20111003/ mas-actualidad/cultura/lopez-nombro-joseba-sarrionaindia-201110031325.html

Hagen, T. (29-11-2014): "Quién no había adivinado el pop en Berri es que no estaba atento", Mondo Sonoro, en http://www.mondosonoro.com/entrevistas/quien-nohabia-adivinado-el-pop-en-berri-es-que-no-estaba-atento/ 
Herreros R. y López, I. (2013): El Estado de las cosas de Kortatu. Lucha, fiesta y guerra sucia, Madrid, Lengua de Trapo.

Jiménez, A. (9-9-2015): El Cascabel, programa emitido en 13 TV, disponible en https://www. youtube.com/watch?v=dYLG0f6LEdy

Jones, O. (2015): El Establishment. La casta al desnudo, Barcelona: Seix Barral.

Larrínaga, J. (2014): Ttakun eta scrath: Euskal pop musikaren hotsak, Leioa, UPV/EHU.

Lenore, V. (2014): Indies, hípsters y gafapastas. Crónica de una dominación cultural, Madrid, Capitán Swing.

Letamendia, F. (1997): Juego de espejos. Conflictos nacionales centro-periferia, Madrid, Trotta.

Letamendia, F. (2013): El hilo invisible: identidades políticas e ideologías, Bilbao, UPV-EHU.

López Romo, R. (2011): Años en claroscuro: nuevos movimientos sociales y democratización en Euskadi (1975-1980), Bilbao, UPV/EHU.

López Romo, R. (2015): Informe Foronda. Los efectos del terrorismo en la sociedad vasca, Madrid, Catarata.

Martínez, J.A. (2006): «El lenguaje (políticamente) correcto», Lección inaugural del Curso 2006-2007, Universidad de Oviedo: septiembre 2006, disponible en: http://www. pensamientocritico.org/josmar1106.html. Véase también BARRAYCOA, Javier: «Lo políticamente correcto. Una revolución semántica», Verbo, n. o 391-392, 2001, pp. 51-61.

Méndez, L. (09-05-2009): «Rock and roll lehendakari», El Mundo, en http://www.elmundo. es/opinion/columnas/lucia-mendez/2009/05/14629501.html

Monge, C. (2017): 15M. Un movimiento político para democratizar la sociedad, Zaragoza, Prensas de la Universidad de Zaragoza.

Mota, D. (13-10-2018): «El Rock Radikal Vasco cumple 35 años», El Correo On+. Tiempo de Historias.

Mota, D. (2016). «¿Fuimos ratas en Bizkaia? Las letras de Eskorbuto y su crítica sociopolítica (1983-1988), en C. Collado (ed.): Himnos y canciones. Imaginarios colectivos, símbolos e identidades fragmentadas en la España del siglo XX, Granada, Comares, 335-354. 
Mota, D. (2017a): «Hoy es el futuro. Euskal underground musika mugimenduaren instrumentalizazioa 1980ko hamarkadan», Mediatika, 16, 37-50.

Mota, D. (2017b): «La música underground vasca en la década de los 90. La hegemonía del rock político y su eclipse a otras escenas musicales», Vegueta. Anuario de la Facultad de Geografía e Historia, 17, 515-543.

Mota, D. (2018): «He visto las calles ardiendo otra vez. La estabilización de la escena músico-política en el País Vasco durante la década de 1990. Del caso de Eskorbuto al de Negu Gorriak», Historia Contemporánea, 58, pp. 413-451.

Ochoa, A. (04-02-2015): "Las tres caras de Berri Txarrak», Diagonal, https://www. diagonalperiodico.net/culturas/25570-tres-caras-berri-txarrak.html

Pascual, J. (2015): Movimiento de Resistencia. Años 80 en Euskal Herria: contexto, crisis y punk, Tafalla, Txalaparta.

Paskual, I. (2013): «El rock en España 1990-2010. Del espíritu olímpico a la Ley del Suelo», en K. Mora y E. Viñuela: Rock around Spain. Historia, industria, escenas y medios de comunicación, Lleida, Edicions de la Universitat de Lleida.

Pennissi, A. y Cangi, A. (2016): Linchamientos. La policía que llevamos dentro, Buenos Aires, Quadratta.

Porrah, H. (2006): Negación punk en Euskal Herria, Tafalla, Txalaparta.

Prado, Á. (25-04-2008): «Berri Txarrak», RockInSpain, en www.rockinspain.es/cronicas/ berri-txarrak

Purkis, J. y Bowen, J. (2004): Changing anarchism. Anarchist theory and practice in a global age. Manchester, Manchester University Press.

Ramos, M.D. (2008): «¿Un mundo feliz? Los nuevos movimientos sociales. Entre el bienestar, la igualdad y la diferencia», en A. Rivera et al.: Movimientos sociales en la España contemporánea. Madrid, Abada Editores.

Rivera, A. (2015): «No estábamos solos y no lo vimos. Memoria e historia de la transición», en M. Toral (ed.): La calle es nuestra. La Transición en el País Vasco 1973-1982, Bilbao, Kultura Abierta.

Romero, G. (10-5-2018): «Juego y Dogma en la política y justicia española», Gara, 10-5-2018, en https://www.naiz.eus/fr/iritzia/articulos/juego-y-dogma-en-la-politica-y-justiciaespanola. 
Romero, G. (2018): «El Rock Radical Vasco. La constitución de los sujetos políticos a través de la música», Inguruak, 64, 24-40.

Sabaté, D. (08-11-2011): «El hilo de la vida», Mondo Sonoro, en www.mondosonoro.com/ entrevistas/el-hilo-de-la-vida/

Sáenz del Castillo, Aritza (2012): «Jaungoikoak Lehendakaria Babes Dezala! Euskal Herriko Rock Erradikaleko Erretorikaren Interpretazio Libertarioa», Sancho el Sabio, 35, 119-141.

Sarría Buil, A. (2006): "Contraofensiva desde el exilio editorial a la propaganda franquista», en M. Aznar Soler (ed.): Escritores, editoriales y revistas del exilio republicano de 1939, Sevilla, Renacimiento.

Simón, P. (09-12-2012): "La Constitución de 1978 y la crisis del régimen», Politikon, en http://politikon.es/2012/12/09/la-constitucion-de-1978-y-la-crisis-del-regimen/

Soto Ivars, J. (2016). Arden las redes. La postcensura y el nuevo mundo virtual, Barcelona, Debate.

Teruel, A. (05-07-2015): «En Francia no se toca a los guiñoles», El País, en http://cultura. elpais.com/cultura/2015/07/04/television/1436031763_679173.html

Usó, J.C. (2015): ¿Nos matan con heroína? Sobre la intoxicación farmacológica como arma de Estado, Bilbao, Libros Crudos.

Vilarós, T.M. (2018): El mono del desencanto. Una crítica cultural de la transición española (1973-1993), Madrid, Siglo XXI.

Zizek, S. (2011): El acoso de las fantasías, Madrid, Akal.

Zuloaga, J.M. (26-07-2011): «Objetivo: volver a tomar la calle», La Razón, en http://www. larazon.es/historico/4145-objetivo-volver-a-tomar-la-calle-ULLA_RAZON_388663\#. Ttt1kXFDoYOZg17 